Research Article

\title{
Relationship between Learning Approaches and Academic Performance of Dental Students: A Cross-Sectional Study in Kermanshah, Iran
}

\author{
Narges Ziaei $\mathbb{D}^{1},{ }^{1}$ Marzie Shaveisi, ${ }^{2}$ Maryam Janatolmakan $\mathbb{D}^{\mathbb{D}},{ }^{3}$ Roya Safari Bahramani $\mathbb{D}^{4},{ }^{4}$ \\ and Alireza Khatony iD ${ }^{5,6}$ \\ ${ }^{1}$ School of Dentistry, Periodontics Department, Kermanshah University of Medical Sciences, Kermanshah, Iran \\ ${ }^{2}$ Student Research Committee, Kermanshah University of Medical Sciences, Kermanshah, Iran \\ ${ }^{3}$ Clinical Research Development Center, Imam Reza Hospital, Kermanshah University of Medical Sciences, Kermanshah, Iran \\ ${ }^{4}$ Research Center for Environmental Determinants of Health, Kermanshah University of Medical Sciences, Kermanshah, Iran \\ ${ }^{5}$ Social Development and Health Promotion Research Center, Health Institute, Kermanshah University of Medical Sciences, \\ Kermanshah, Iran \\ ${ }^{6}$ Infectious Diseases Research Center, Kermanshah University of Medical Sciences, Kermanshah, Iran
}

Correspondence should be addressed to Alireza Khatony; akhatony@gmail.com

Received 20 September 2021; Revised 10 October 2021; Accepted 11 October 2021; Published 18 October 2021

Academic Editor: Ehsan Namaziandost

Copyright ( 2021 Narges Ziaei et al. This is an open access article distributed under the Creative Commons Attribution License, which permits unrestricted use, distribution, and reproduction in any medium, provided the original work is properly cited.

Background. Learning approaches are a set of skills and strategies used by learners to organize and recall the content. Teachers can adopt appropriate teaching methods if they know the students' learning approaches. This study was conducted to determine the relationship between learning approaches and academic performance of dental student. Methods. In this cross-sectional study, 128 dental students of Kermanshah University of Medical Sciences were recruited by the stratified random sampling method. The data collection tools were a demographic information form and Approaches and Study Skills Inventory for Students (ASSIST). To determine academic performance, the grade point average (GPA) of the previous semester was used, and students with GPA scores $\leq 14.99$ and $\geq 15$ were divided into weak and strong groups, respectively. Data were analyzed by SPSS 17 software using descriptive and inferential statistics. Results. The most common learning approach in most strong $(n=49,45.4 \%)$ and weak $(n=12,60 \%)$ students was the superficial approach. The results of the chi-square test did not show a statistically significant difference between strong and weak students in terms of the learning approach. Conclusion. The results did not show a statistically significant relationship between students' learning approach and their academic performance. However, since the superficial approach can lead to a decline in academic performance, the professors need to take the necessary intervention measures to improve students' learning approaches. Further studies with larger sample sizes are recommended to shed more light on this research domain.

\section{Introduction}

Learning approaches are the ways in which students organize learning activities [1]. In other words, learning approaches are techniques that can be used to increase study efficiency [2]. Learning approaches are divided into three types: deep, superficial, and strategic [3-8]. In the depth approach, students have an innate interest in reading and critically examine their ideas [9]. They connect previous and new knowledge, experience, and daily tasks and gain new insights [4]. In the superficial approach, students see the university as a suitable tool for getting a job and rely on parrot learning, but in the strategic approach, students try to get the highest score. For this reason, they need proper time management and proper study organization $[5,10]$. Learning approaches play an important role in determining students' academic performance $[1,2]$. Recent research has also emphasized the importance of students' learning 
approach as a determinant of academic performance [1]. On the other hand, if necessary, measures are taken to change students' learning approaches during the codified educational programs, and their approach may change $[7,11]$.

Regarding the frequency of learning approaches in students, several studies have reported contradictory results $[5,7,8,12-15]$. Furthermore, several studies have shown contradictory results for the relationship between different approaches to learning and academic performance $[5,7,8,12-15]$. Some studies have indicated a negative correlation between the academic performance and superficial approach $[16,17]$ and a positive correlation between deep and strategic approaches and academic performance [18-20]. However, some studies have reported no relationship between the learning approach and academic performance [16, 21-23].

Due to the contradictory results of previous studies and the lack of information about the dominant approach to learning and its relationship with academic performance in dental students in Kermanshah, Iran, the present study was conducted to shed more light on this research domain.

This study sought to answer the following questions. (1) What is the frequency of learning approaches in dental students? (2) What is the academic performance of dental students? and (3) What is the relationship between learning approaches and academic performance of dental students?

1.1. Literature Review. The main purpose of education is effective learning in students [8]. There are many factors involved in students' learning, one of the most important of which is learning approaches [24]. In this regard, several studies have examined the relationship between learning approaches and students' academic performance, the results of which are different. In a study aimed at determining the relationship between learning approaches and academic performance of 370 medical students in Iran, the results showed that the mean score of the in-depth approach was higher than that of the superficial approach, and a positive correlation was found between this approach and academic performance [13]. In another study in Saudi Arabia, the relationship between learning approaches of 610 medical students and their academic performance was examined. The results indicated the in-depth approach was the most common learning approach that had a significant relationship with academic performance [12]. A study (2004) in Australia examined the relationship between the learning approach and academic performance in 49 psychology students. The results showed that the dominant learning approach was the in-depth approach, which had a statistically significant relationship with academic performance [22].

In two studies in Norway and the United States, the indepth approach was the dominant approach to student's learning, which had a significant relationship with academic performance $[16,21]$. The results of a study conducted on English students showed that students who used the indepth approach had better academic performance than students who used superficial and strategic approaches [20].
In a study on Iranian students, the most common learning approaches included in-depth, strategic, and superficial approaches, respectively, and there was a statistically significant relationship between strategic and superficial approaches and academic performance [2]. The results of a study conducted on 192 students in Norway showed that only superficial and strategic approaches had a statistically significant relationship with academic performance [25]. In a study conducted in England (2000), the relationship between learning approaches and academic performance of 1284 students from six universities was examined, and the results showed a significant relationship between in-depth and superficial approaches and academic performance [18]. In this regard, the results of a study (2007) conducted on 332 students of psychology and educational management in Iran indicated a significant relationship between in-depth and superficial approaches and students' academic performance, so that the mean scores of in-depth and superficial approaches were higher in students with good academic performance and lower in students with poor academic performance, respectively [26]. The results of a study conducted on Australian students showed that the predominant approach to learning was the superficial approach, which had a significant inverse correlation with academic performance [23]. In a study on 227 American students, the results showed no statistically significant relationship between the learning approach and academic performance [21].

The results of a literature review indicate that the dominant approach to learning in students is different and the type of relationship between learning approaches in the existing studies has been reported differently. Given the importance of using the in-depth approach, educators need to make the necessary plans to encourage students to use this approach [27].

\section{Materials and Methods}

2.1. Study Design. This cross-sectional descriptive-analytical study was performed in Kermanshah Dental School. In this type of study, the relationship between exposure and outcome is examined simultaneously, in a specific population and at a specific time point [28].

2.2. Sample and Sampling Method. The study population included dental students of Kermanshah University of Medical Sciences. The research sample included 150 dental students. The sample size was calculated using based on the study of Mehdinezhad and Esmaeeli [29]. Considering the prevalence of 0.47 for the strategic learning approach, alpha level of 0.05 , error level of 0.18 , and nonresponse probability of $10 \%$, a sample size of 150 people was calculated. Sampling was performed by the stratified random sampling method. For this purpose, the names of students according to the academic year were obtained from the Department of Education. Students in each academic year formed a stratum. Inside each stratum, random sampling was performed using a random number table. The sample size selected from each 
academic year was proportional to the percentage of students in that year.

2.3. Measurement Instruments. Data collection tools included a demographic information form and Approaches and Study Skills Inventory for Students (ASSIST). The demographic information form included 5 questions on age, gender, residence, marital status, and grade point average (GPA) of the previous semester ( $s$ ). To determine the status of academic performance, the GPA of the previous semester was used, and the samples were divided into two categories of strong $(\mathrm{GPA} \geq 15)$ and weak (GPA $\leq 14.99)$ [30, 31].

ASSIST is a tool used to measure learning approaches in deep, strategic, and superficial dimensions. This tool was developed by Entwistle and Tait [2]. ASSIST has been psychometrized in previous studies $[2,29,32]$. In the study of Liew et al. (2015), Cronbach's alpha coefficients for deep, superficial, and strategic approaches were reported to be $0.85,0.81$, and 0.83 , respectively [32]. In this regard, Shakurnia et al. (2012), while confirming the construct validity of the questionnaire, reported Cronbach's alpha coefficients of $0.84,0.70$, and 0.80 for deep, strategic, and superficial approaches, respectively [2]. The Persian version of ASSIST was psychometrically assessed by Mehdinezhad and Esmaeeli, and the internal consistency scores of the instrument by Cronbach's alpha method for superficial, deep, and strategic approaches were reported to be $0.62,0.78,0.81$, and 0.87 , respectively [29]. In the present study, the internal consistency of the instrument was examined by Cronbach's alpha method, and the alpha values for deep, superficial, and strategic approaches were calculated to be $78 \%, 79 \%$, and $78 \%$, respectively.

ASSIST has 52 questions, with 16, 20, and 16 questions on the deep, strategic, and superficial domains, respectively. The questions are of the five-point Likert scale type, including agree, somewhat agree, uncertain, somewhat disagree, and disagree, which are scored from 5 to 1 , respectively. The range of scores for each of these three approaches is between 4 and 20. The Byrne method was used to determine the type of the learning approach for each student [18]. For this purpose, first the total score of the questions of each approach was determined. In the next step, the average score of each approach was calculated. For this purpose, the total scores of each of the deep, superficial, and strategic approaches were divided into 4, 4, and 5, respectively. Finally, according to the calculated mean, the type of learning approach was determined. To this end, the main approach to learning was the one that had the highest average. Earning equal points in two or three approaches would lead to exclusion of the student from the study $[2,14]$. In the current study, 22 students were excluded for this reason.

2.4. Data Gathering. After obtaining the approval of the University Ethics Committee, the researcher referred to the Education Department of the School of Dentistry and received a list of students. After randomly selecting the names of the students in each academic year, the researcher referred
TABLE 1: Demographic characteristics of the students $(N=128)$.

\begin{tabular}{lcc}
\hline \multicolumn{2}{c}{ Variables } & $N(\%)$ \\
\hline \multirow{2}{*}{ Age (years) } & $<22$ & $32(25)$ \\
& $\geq 22$ & $96(75)$ \\
Sex & Male & $58(45.3)$ \\
\multirow{2}{*}{ Marital status } & Female & $70(54.7)$ \\
\multirow{2}{*}{ Residence } & Single & $110(85.9)$ \\
\multirow{2}{*}{ Academic performance } & Married & $18(14.1)$ \\
& Dormitory & $39(30.5)$ \\
& With family & $89(69.5)$ \\
& Strong (GPA* $\geq 15)$ & $20(15.6)$ \\
& Weak (GPA $\leq 14.99)$ & $108(84.4)$ \\
\hline
\end{tabular}

${ }^{*}$ Grade point average.

to them according to their class schedule. First, the objectives of the study were explained to them, and if they were willing, the questionnaires were provided to them. The questionnaires were collected after completion.

2.5. Data Analysis. Data were analyzed by SPSS 17 software (SPSS v.17.0; SPSS Inc., Chicago, IL, USA) using descriptive and inferential statistics. In the descriptive statistics section, mean, standard deviation, and frequency distribution tables were used to describe the data. In the analytical statistics section, the independent $t$-test and chi-square test were used. To report the results of different learning approaches, the average scores related to the questions of each approach were calculated. The independent $t$-test was used to compare each of the learning approaches based on two-state qualitative variables, including age, sex, marital status, residence, and academic performance. The level of significance was less than 0.05 .

2.6. Ethical Considerations. The Ethics Committee of Kermanshah University of Medical Sciences approved the study with the code IR.KUMS.REC.1397.537. The objectives of the study were stated for all participants. Written informed consent was obtained from all participants. Emphasis was placed on the confidentiality of the participants' information and characteristics.

\section{Results}

In this cross-sectional study, the samples included 150 dental students. Twenty-two students were excluded from the analysis due to the same acquired scores in two or three areas of the learning and study approaches. Finally, 128 students were included in the study. The mean age of students was $23.9 \pm 2.9$ years. Most students were over 22 years old $(n=96,75 \%)$, female $(n=70,54.7 \%)$, and single $(n=110$, $85.9 \%)$. A total of 89 students (69\%) lived with their families. The GPA of the previous semester $(s)$ in all students was $15.5 \pm 1.1$ out of 20 . In strong and weak students, the GPA scores of the previous semester $(s)$ were $15.8 \pm 0.9$ and $13.8 \pm 0.4$, respectively. Most students $(n=108,84.4 \%)$ had good academic performance (Table 1$)$.

In most strong $(n=49,45.4 \%)$ and weak students $(n=12$, $60 \%$ ), the dominant learning approach was superficial. 
TABLE 2: The relationship between learning approaches and academic performance in strong and weak students.

\begin{tabular}{lccc}
\hline Learning approach & \multicolumn{3}{c}{ Academic performance } \\
& Total, $n(\%)$ & Week students $\left(\mathrm{GPA}^{\theta} \leq 14.99\right)(n=20)$ & Strong students $(\mathrm{GPA} \geq 15)(n=108)$ \\
\hline Superficial & $61(47.7)$ & $12(60.0)$ & $49(45.4)$ \\
Deep & $18(14.1)$ & $4(20.0)$ & $14(13.0)$ \\
Strategic & $49(38.3)$ & $4(20.0)$ & $45(41.7)$ \\
Test result & & $X^{2}=3.421, p=.181$ & \\
\hline
\end{tabular}

${ }^{\theta}$ Grade point average.

TABLE 3: Frequency distribution of learning approaches in strong and weak students in terms of demographic variables $(n=128)$.

\begin{tabular}{|c|c|c|c|c|c|c|c|}
\hline \multirow{3}{*}{\multicolumn{2}{|c|}{ Academic performance }} & \multicolumn{6}{|c|}{ Learning approach, $n(\%)$} \\
\hline & & \multicolumn{3}{|c|}{ Weak students $(n=20)$} & \multicolumn{3}{|c|}{ Strong students $(n=108)$} \\
\hline & & Superficial & Deep & Strategic & Superficial & Deep & Strategic \\
\hline \multirow{2}{*}{ Sex } & Male & $8(53.3)$ & $3(20.0)$ & $4(26.7)$ & $17(39.5)$ & $8(18.6)$ & $18(41.9)$ \\
\hline & Female & $4(80.0)$ & $1(20.0)$ & $0(0.0)$ & $32(49.2)$ & $6(9.2)$ & $27(41.5)$ \\
\hline \multirow{2}{*}{ Age (years) } & $<22$ & $5(71.4)$ & $1(14.3)$ & $1(14.3)$ & $11(44.0)$ & $3(12.0)$ & $11(44.0)$ \\
\hline & $\geq 22$ & $7(53.8)$ & $3(23.1)$ & $3(23.1)$ & $38(45.8)$ & $11(13.3)$ & $34(41.0)$ \\
\hline \multirow{2}{*}{ Marital status } & Single & $10(58.8)$ & $3(17.6)$ & $4(23.5)$ & $43(46.2)$ & $12(12.9)$ & $38(40.9)$ \\
\hline & Married & $2(66.7)$ & $1(33.3)$ & $0(0.0)$ & $6(40.0)$ & $2(13.3)$ & $7(46.7)$ \\
\hline \multirow{2}{*}{ Residence } & Dormitory & $3(60.0)$ & $1(20.0)$ & $1(20.0)$ & $15(44.1)$ & $5(14.7)$ & $14(41.2)$ \\
\hline & With family & $7(63.6)$ & $2(18.2)$ & $2(18.2)$ & $34(45.9)$ & $9(12.2)$ & $31(41.9)$ \\
\hline
\end{tabular}

TABLE 4: The mean scores of learning approaches in strong and weak students in terms of demographic variables $(n=128)$.

\begin{tabular}{|c|c|c|c|c|c|c|c|}
\hline \multirow{2}{*}{\multicolumn{2}{|c|}{ Academic performance }} & \multicolumn{6}{|c|}{ Learning approach, mean $\left(\mathrm{SD}^{\theta}\right)$} \\
\hline & & \multicolumn{3}{|c|}{ Strong students } & \multicolumn{3}{|c|}{ Weak students } \\
\hline & & Deep & Strategic & Superficial & Deep & Strategic & Superficial \\
\hline \multirow{2}{*}{ Sex } & Male & $13.6(2.1)$ & $14.7(1.9)$ & $14.1(2.1)$ & $13.5(1.7)$ & $13.7(1.6)$ & $14.3(1.8)$ \\
\hline & Female & $13.6(1.7)$ & $14.7(2.1)$ & $14.4(2.1)$ & $14.3(2.1)$ & $13.0(3.2)$ & $15.6(0.7)$ \\
\hline \multicolumn{2}{|c|}{$P$ value ${ }^{\ddagger}$} & 0.893 & 0.966 & 0.408 & 0.418 & 0.528 & 0.133 \\
\hline \multirow{2}{*}{ Age } & $<22$ & $13.7(1.8)$ & $14.9(1.7)$ & $14.3(2.3)$ & $13.9(1.8)$ & $13.4(2.5)$ & $14.6(1.8)$ \\
\hline & $\geq 22$ & $13.6(1.8)$ & $14.6(2.0)$ & $14.4(1.9)$ & $13.6(1.9)$ & $13.6(2.1)$ & $14.6(1.6)$ \\
\hline \multicolumn{2}{|c|}{$P$ value ${ }^{\ddagger}$} & 0.792 & 0.517 & 0.830 & 0.707 & 0.281 & 0.919 \\
\hline \multirow{2}{*}{ Marital status } & Single & $13.5(2.1)$ & $14.6(2.0)$ & $14.3(2.1)$ & $13.5(2.1)$ & $13.6(2.2)$ & $14.6(1.7)$ \\
\hline & Married & $14.0(1.5)$ & $15.3(1.2)$ & $14.4(2.1)$ & $15.1(1)$ & $13.5(1.3)$ & $14.5(1.2)$ \\
\hline \multicolumn{2}{|c|}{$P$ value ${ }^{\ddagger}$} & 0.314 & 0.072 & 0.839 & 0.337 & 0.981 & 0.892 \\
\hline \multirow{3}{*}{ Residence } & Dormitory & $14.1(1.9)$ & $14.6(2.1)$ & $14.6(1.9)$ & $14.0(2.7)$ & $14.5(1.8)$ & $14.2(2.1)$ \\
\hline & With family & $14.1(1.8)$ & $14.9(2.1)$ & $14.2(2.1)$ & $14.1(1.4)$ & $13.5(2.3)$ & $14.6(1.1)$ \\
\hline & & 0.980 & 0.501 & 0.409 & 0.957 & 0.281 & 0.745 \\
\hline
\end{tabular}

${ }^{\theta}$ Standard deviation. ${ }^{*}$ Based on the independent $t$-test. ${ }^{\dagger}$ Based on analysis of variance.

The chi-square test did not show a statistically significant difference between strong and weak students in terms of learning and study approaches (Table 2).

In strong students, the predominant learning approach in most male $(n=8,53.3 \%)$ and female $(n=32,49.2 \%)$ students were strategic and superficial, respectively. However, in weak students, the predominant learning approach was the superficial approach in most male $(n=8,53.3 \%)$ and female $(n=4,80 \%)$ students.

In strong students under 22 years of age, superficial and strategic approaches, with equal frequency $(n=11$, $44.0 \%$ ), were the dominant learning approaches. But in the age group over 22 years $(n=38,45.8 \%)$, the dominant learning approach in strong students was the superficial approach. However, in weak students, in both age groups higher $(n=7,53.8)$ and lower $(n=7,71.4 \%)$ than 22 years, the superficial approach was the most common learning approach.

In strong students, the predominant learning approaches in most single $(n=43,46.2 \%)$ and married $(n=7,46.7 \%)$ students were superficial and strategic approaches, respectively, but in weak students, the most common approach to learning was the superficial approach in both single $(n=10$, $58.8 \%)$ and married ( $n=2,66.7 \%)$ groups.

In strong students, the predominant learning approach in dormitory $(n=15,44.1 \%)$ and nondormitory students $(n=34,45.9 \%)$ was the superficial approach. In weak students in both dormitory $(n=3,60.0 \%)$ and nondormitory $(n=7,63.6 \%)$ groups, the dominant learning approach was the superficial approach (Table 3 ).

The results of the independent $t$-test showed no statistically significant difference between the mean learning 
approaches in each group of strong and weak students in terms of gender, age, marital status, and residence (Table 4).

\section{Discussion}

This study aimed to determine the relationship between learning approaches and academic performance of dental students. In the present study, the most common learning approach was the superficial approach in all students and in most strong and weak students. This finding is consistent with the results of some studies $[33,34]$, but not in line with those of others $[6,7,31]$. In a number of studies, the predominant learning approaches have been deep $[5,7,12,13,32,35]$ and strategic $[6,7,31]$ approaches. This discrepancy in the results can be due to factors that affect the choice of students' learning approach, such as intrinsic motivation, learning environment, teaching methods, interest in the study subject, and students' evaluation [35]. When students study for the fear of failure, they are more likely to resort to superficial approach strategies such as parrot-like conservation. When their motivation for reading is to understand the underlying meaning of the material, they use deep strategies $[11,36]$.

The results showed no statistically significant difference between strong and weak students in terms of the learning approach. This finding is consistent with the results of Shakurnia et al.'s study [2]. However, in a number of studies, a statistically significant relationship has been reported between learning approaches and academic performance $[16,33,37,38]$. In this regard, Akbari et al. showed a direct relationship between deep and strategic approaches and academic performance, but the relationship between the superficial approach and academic performance was inverse [27]. This means that students who use deep and strategic approaches have good academic performance, but the relationship is reverse in those who use the superficial approach.

However, evidence suggests that the learning approach may change in different situations, so that in some situations, students with good academic performance may use the superficial approach due to factors such as the teacher's evaluation method [11]. On the other hand, it seems that having a black and white view of the superficial approach is not correct, and this approach may sometimes be more effective than the deep approach [18]. However, there is evidence that academic performance is greater among learners who use the deep approach $[2,39]$. Therefore, in order to improve the quality of education and increase students' academic performance, students' learning approaches should be considered.

The results showed that in the strong students, the dominant learning approaches in most male and female students were strategic and superficial approaches, respectively, but in the weak students, the dominant learning approach was the superficial approach in most male and female students. There was no statistically significant difference between male and female students in terms of the learning approach. Some studies have reported no difference between female and male students in terms of learning approaches $[5,6,33,40-43]$, while some studies have shown a statistically significant difference $[13,14,43,44]$. In these studies, learning approaches were significantly different between female and male students. In this regard, Chonkar et al. indicated that the frequency of the strategic approach was significantly lower in male students than in female students [44]. Evidence suggests that female students are far more likely than male students to take a deep approach and that factors such as partiality and greater willingness to interact socially with classmates play a role in this regard [38]. Learning approaches are not fixed and can change over time and in different situations [44]. Differences between our results and those of previous studies can be related to issues such as differences in the individual characteristics of the samples, the learning environment, and the teaching and evaluation methods of the professors.

The results of this study showed that in strong students, the predominant learning approaches in most single and married students were superficial and strategic approaches, respectively, while in week students, the most common learning approach in both single and married groups was the superficial approach. There was no statistically significant difference between single and married students in terms of the learning approach. Despite searching multiple databases such as Scopus and PubMed, the authors were unable to find evidence of a relationship between the marital status and learning approach. Although no statistically significant relationship was found between the learning approach and marital status in the present study, professors should take the necessary steps to improve the weak students' learning approach, considering the evidence on the relationship between the deep approach and academic achievement [2].

The results showed that in strong and weak students, the dominant learning approach in dormitory and nondormitory students was the superficial approach, and there was no statistically significant difference between them in terms of the learning approach. A review of literature shows the relationship between the learning approach and the student's residence has not been addressed so far. However, given the negative relationship between the academic performance and superficial approach [39, 45], educators should take steps to improve students' learning approach regardless of location.

In strong students, the predominant learning approaches in the age group $<22$ were superficial and strategic approaches, but the predominant learning approach in the age group $>22$ was the superficial approach. In weak students, the superficial approach was the most common learning approach in both age groups. No significant differences were found between the age groups and the learning approach. Some studies have shown no statistically significant relationship between the dominant learning approach and age $[7,32,46]$. However, one study indicated a significant relationship, and the use of deep, strategic, and superficial approaches was different between age groups [29]. Differences in the results of our study with those of this study can be related to issues such as personality traits of samples, learning environment, teaching methods, as well as the professors' evaluation method. 
4.1. Limitation. This study faces two limitations. The data collection method was self-report, which could have affected the accuracy of the results. Another limitation was related to the nature of cross-sectional studies, which is not possible to determine the cause and effect relationships between the study variables, and the current study is no exception to this rule.

\section{Conclusion}

The most common learning approach was the superficial approach in all students and in most strong and weak students. No statistically significant relationship was found between the learning approach and academic performance. However, since the superficial approach can lead to a decline in students' academic performance, it can have negative consequences for future recipients of dental services due to the therapeutic nature of the dental profession. According to the evidence, which shows a relationship between the deep approach and academic performance, professors are required to take the necessary intervention measures to improve the dental students' learning approaches. On the other hand, dental professors, knowing the students' learning approach, can use appropriate teaching methods to teach them effectively. Further studies in other medical disciplines with larger sample sizes are recommended to explore this issue.

\section{Data Availability}

The identified datasets analyzed during the current study are available from the corresponding author upon request.

\section{Conflicts of Interest}

The authors declare there are no conflicts of interest.

\section{Authors' Contributions}

NZ, MS, MJ, RSB, and AK contributed in designing the study. MS collected the data, and data were analyzed by RSB. The final report and manuscript were written by NZ, MS, MJ, RSB, and AK. All the authors read and approved the version for submission.

\section{Acknowledgments}

This study was the result of a dissertation of Marzie Shaveisi, a dental student, funded by the Kermanshah University of Medical Sciences (97830). The authors would like to thank all the students who participated in this study. The authors also extend their thanks to the Clinical Research Development Center of Imam Reza Hospital affiliated to Kermanshah University of Medical Sciences for their kind support.

\section{References}

[1] M. Bahreini and K. Mirzaei, "Learning approaches of undergraduate nursing and midwifery students: a longitudinal study," Iranian Journal of Medical Education, vol. 18, pp. 363-371, 2018.

[2] A. Shakurnia, H. Alijani, H. Elhampour, and M. Afra, "Nursing and Midwifery students' approaches to study and learning in AJUMS," IJNR, vol. 7, no. 26, pp. 57-68, 2012.

[3] P. R. Shankar, R. Balasubramanium, and N. R. Dwivedi, "Approach to learning of medical students in a Caribbean medical school," Education in Medicine Journal, vol. 6, no. 2, 2014.

[4] S. Subasinghe and D. Wanniachchi, "Approach to learning and the academic performance of a group of medical students-any correlation," Studia Medyczne J, vol. 3, no. 1, pp. 5-10, 2009.

[5] D. K. Shah, R. Lochan Yadav, D. Sharma et al., "Learning approach among health sciences students in a medical college in Nepal: a cross-sectional study," Advances in Medical Education and Practice, vol. 7, p. 137, 2016.

[6] D. P. Wickramasinghe and D. N. Samarasekera, "Factors influencing the approaches to studying of preclinical and clinical students and postgraduate trainees," BMC Medical Education, vol. 11, no. 1, p. 22, 2011.

[7] S. P. Chonkar, T. C. Ha, S. S. H. Chu et al., "The predominant learning approaches of medical students," BMC Medical Education, vol. 18, no. 1, p. 17, 2018.

[8] S. Ee, S. Dane, M. Kaya, and R. Yigitoglu, "Medical students' approaches to learning and study skills," Procedia-Social and Behavioral Sciences, vol. 93, pp. 732-736, 2013.

[9] V. Mogre and A. Amalba, "Approaches to learning among Ghanaian students following a PBL-based medical," Education in Medicine Journal, vol. 7, no. 1, 2015.

[10] S. Baroghi-Gholami, M. Yazdankhah-Frad, M. Bahreini, and K. Mirzaei, Investigating the Learning Approaches of Bushehr Nursing and Midwifery Students, Busheher School of Nursing and Midwifery: Busheher University of Medical Sciences, Bushehr, Iran, 2014.

[11] A. Seif and J. Fathabaadi, "Study approaches and its relationship with academic achievement, gender, and duration of study at university," Knowledge of behavior, vol. 15, no. 33, pp. 29-40, 2008.

[12] S. A. Shaik, A. Almarzuqi, R. Almogheer, O. Alharbi, A. Jalal, and M. Alorainy, "Assessing Saudi medical students learning approach using the revised two-factor study process questionnaire," International Journal of Medical Education, vol. 8, pp. 292-296, 2017.

[13] E. Shahrabadi, M. Rezaeian, and A. Haghdoost, "The relationship of study and learning approaches with students' academic achievement in rafsanjan university of medical sciences," Iranian Journal of Medical Education, vol. 13, no. 10, pp. 860-868, 2014.

[14] R. Rehman, R. Khan, M. A. Akahai, and F. Hassan, "Approach of freshly-inducted medical students towards learning at bahria university medical \& dental college," JPMA. The Journal of the Pakistan Medical Association, vol. 63, no. 3, pp. 320-323, 2013.

[15] L. Samarakoon, T. Fernando, C. Rodrigo, and S. Rajapakse, "Learning styles and approaches to learning among medical undergraduates and postgraduates," BMC Medical Education, vol. 13, no. 1, p. 42, 2013.

[16] А. Diseth, "Personality and approaches to learning as predictors of academic achievement," European Journal of Personality, vol. 17, no. 2, pp. 143-155, 2003.

[17] N. Entwistle and P. Ramsden, "Understanding student learning (kent, croom helm)," Degrees of Excellence: The Academic Achievement Game, Entwistle, Nj \& Wilson, London, UK, 1977. 
[18] N. Entwistle, H. Tait, and V. McCune, "Patterns of response to an approaches to studying inventory across contrasting groups and contexts," European Journal of Psychology of Education, vol. 15, no. 1, pp. 33-48, 2000.

[19] N. Nejat, H. Kouhestani, and K. Rezaei, "Effect of concept mapping on approach to learning among nursing students," Hayat, vol. 17, no. 2, 2011.

[20] S. E. Newstead, "A study of two "Quick-and-easy" methods of assessing individual differences in student learning," British Journal of Educational Psychology, vol. 62, no. 3, pp. 299-312, 1992.

[21] R. A. Davidson, "Relationship of study approach and exam performance," Journal of Accounting Education, vol. 20, no. 1, pp. 29-44, 2002.

[22] A. Minbashian, G. F. Huon, and K. D. Bird, "Approaches to studying and academic performance in short-essay exams," Higher Education, vol. 47, no. 2, pp. 161-176, 2004.

[23] P. Booth, P. Luckett, and R. Mladenovic, "The quality of learning in accounting education: the impact of approaches to learning on academic performance," Accounting Education, vol. 8, no. 4, pp. 277-300, 1999.

[24] F. M. Yazdankhah, B. S. Gholami, M. Bahreini, and K. Mirzae, Learning Approaches of Undergraduate Nursing and Midwifery Students: A Longitudinal Study, Busheher University of Medical Sciences, Bushehr, Iran, 2018.

[25] $\AA$. Diseth and $\varnothing$. Martinsen, “Approaches to learning, cognitive style, and motives as predictors of academic achievement," Educational Psychology, vol. 23, no. 2, pp. 195-207, 2003.

[26] J. Fathabadi and A. Saif, "Investigating the effects of type of assessment (essay and multiple-choice) on students' approaches to studying and exam preparation strategies between students with high and low academic achievement," Journal of Educational Scinces, vol. 14, no. 4, pp. 21-46, 2008.

[27] M. Akbari, J. Fathabadi, I. Almasi, and J. Mohammadzadeh, "Relationship between study approaches with academic achievement and student's conception of learning," Research in Curriculum Planning, vol. 16, no. 61, pp. 75-84, 2019.

[28] G. LoBiondo-Wood and J Haber, Nursing Research E-Book: Methods and Critical Appraisal for Evidence-Based Practice, Elsevier Health Sciences, Amsterdam, Netherlands, 2021.

[29] V. Mehdinezhad and R. Esmaeeli, "Students' approaches to learning superficial, strategic and deep," Bimonthly of Education Strategies in Medical Sciences, vol. 8, no. 2, pp. 83-89, 2015.

[30] H. R. Mozaffari, M. Janatolmakan, R. Sharifi, F. Ghandinejad, B. Andayeshgar, and A. Khatony, "The relationship between the VARK learning styles and academic achievement in Dental Students," Advances in Medical Education and Practice, vol. 11, pp. 15-19, 2020.

[31] N. Kouhan, M. Janatolmakan, M. Rezaei, and A. Khatony, "Relationship between Learning Styles and Academic Performance Among Virtual Nursing Students: A Cross-Sectional Study," Education Research International, vol. 2021, Article ID 8543052, 6 pages, 2021.

[32] S.-C. Liew, J. Sidhu, and A. Barua, "The relationship between learning preferences (styles and approaches) and learning outcomes among pre-clinical undergraduate medical students," BMC Medical Education, vol. 15, no. 1, p. 44, 2015.

[33] M. A. Ladan, F. Balarabe, D. Sani, H. Musa, A. Salihu, and M. Salihu, "Learning approaches as predictors of academic performance of undergraduate students in Ahmadu Bello Universiy, Zaria," IOSR Journal of Nursing and Health Science, vol. 3, no. 3, 2014.
[34] A. Mahmoodzadeh, A. Javadi, and Y. Mohammadi, "Relationship between studying approaches and academic performance in students of Birjand University of Medical Sciences," Research in medical education, vol. 8, no. 3, pp. 9-16, 2016.

[35] H. G. Mahmoud, K. E. Ahmed, and E. A. Ibrahim, "Learning styles and learning approaches of bachelor nursing students and its relation to their achievement," International Journal of Nursing Didactics, vol. 09, no. 03, pp. 11-20, 2019.

[36] M. Yazdankhah Fard, S. Gholami, M. Bahraini, and K. Mirzaei, A Study of Learning Approaches of Nursing and Midwifery Students of Bushehr University of Medical Sciences, Bushehr University of Medical Sciences, Bushehr, Iran, 2014.

[37] R. M. Felder and R. Brent, "Understanding student differences," Journal of Engineering Education, vol. 94, no. 1, pp. 57-72, 2005.

[38] S. Kamari and M. Fouladchang, "The Relationship between learning approaches and academic achievement in humanities and engineering students considering the role of gender," Educational and Scholastic studies, vol. 5, no. 2, pp. 129-152, 2016.

[39] H. Asikainen and D. Gijbels, "Do students develop towards more deep approaches to learning during studies? A systematic review on the development of students' deep and surface approaches to learning in higher education," $E d u$ cational Psychology Review, vol. 29, no. 2, pp. 205-234, 2017.

[40] A. Duff, "The revised approaches to studying inventory (RASI) and its use in management education," Active Learning in Higher Education, vol. 5, no. 1, pp. 56-72, 2004.

[41] C. Kreber, “The relationship between students' course perception and their approaches to studying in undergraduate science courses: a Canadian experience," Higher Education Research and Development, vol. 22, no. 1, pp. 57-75, 2003.

[42] A. Shakurnia, H. Elhampour, B. M. Ghafourian, and S. R. Saeidian, "Nursing and medical students'studying and learning approaches," Jentashapir journal of health research, vol. 2, no. 4, pp. 201-210, 2012.

[43] A. H. Shakurnia, M. GHaforian, and H. Elhampour, "Approaches to study and learning of students in ahvaz JundiShapur university of medical sciences," Jundishapur Scientific Medical Journal, vol. 11, no. 6, pp. 577-586, 2013.

[44] S. P. Chonkar, T. C. Ha, S. S. H. Chu et al., "The predominant learning approaches of medical students," BMC Medical Education, vol. 18, no. 1, pp. 17-18, 2018.

[45] M. C. W. Ee, "Differences in learning and study strategies between high and low achieving university students: a Hong Kong study," Educational Psychology, vol. 27, no. 5, pp. 597-606, 2007.

[46] S. Ahmadi, Z. Jouhari, and F. Haghani, "Medical and dental students' learning and study strategies in shahed university," Iranian Journal of Medical Education, vol. 13, no. 10, pp. 886-896, 2014. 